\title{
The True Idea of Mendel's Assumption regarding the Gene Is Rediscovered
}

\author{
Muying Zhou \\ The Central Hospital of Shandong Feicheng Coal-Mining Group Corporation, Taian, China \\ Email: fckzmy@sina.com
}

How to cite this paper: Zhou, M.Y. (2020) The True Idea of Mendel's Assumption regarding the Gene Is Rediscovered. Open Journal of Genetics, 10, 1-7.

https://doi.org/10.4236/ojgen.2020.101001

Received: November 26, 2019

Accepted: December 20, 2019

Published: December 23, 2019

Copyright $\odot 2020$ by author(s) and Scientific Research Publishing Inc. This work is licensed under the Creative Commons Attribution International License (CC BY 4.0).

http://creativecommons.org/licenses/by/4.0/

\section{(c) (i) Open Access}

\begin{abstract}
The question of whether the "synthetic life" created by J.C. Venter was produced by DNA (the genome) also raises the question of whether the basic ideas behind modern genetics (germplasm $=$ the hereditary material of the germ cells $=$ genes) are true. In theory, however, whether genes can produce cells (including traits) should depend on Mendel's assumptions regarding genes and not on what people can argue or discuss at will. Consequently, the author studied Mendel's assumptions again. It turns out, unexpectedly, that the gene refers to a hereditary element controlling the specifications of the individual rather than the producer of the individual. That is to say, the gene is a facilitator, and the acceptor produces the individual by following the specifications set by the gene. This is the most significant genetics-related discovery since Mendel's death, Scientific facts, including Avery's experiment, consistently proved that this is true.
\end{abstract}

\section{Keywords}

Genes, Hereditary Material, Genetics, Template, Producer

\section{Introduction}

It is generally believed that "modern genetics", which regards Mendel as the "father of genetics", has a correct understanding of Mendel's assumptions regarding genes. However, a storm in 2010 made this idea shaken.

In 2010, J.C. Venter said that they had created a man-made genome (of $M Y$ coplasma mycoides) and had used it to make "synthetic life" [1] [2]. This means: genes (genome) are the producer of the individual (cell). That is consistent with the "modern genetics" consensus: "germplasm: the hereditary material of the germ cells: genes" [3].

However, Dr. Gerald Joyce, an internationally renowned life scientist at the 
Scripps Institute in California, said in the $\langle$ New York Times $\rangle$ : "Dr. Venter copied the DNA from one species of bacteria and inserted it into another. The second bacteria made all the proteins and organelles in the so-called 'synthetic cell' by following the specifications implicit in the structure of the inserted DNA" [2]. This means: genes (genome) are not the producer of the individual (cell).

Now there are two contradictory judgments that cannot both be true.

Identifying the correct statement would directly determine the fate of "modern genetics". If genes are the producer of the individual (cell), then "modern genetics" is right; However, if genes are not the producer of the individual (cell), then genes cannot be the hereditary material, and the basis of "modern genetics" (in which genes are regarded as the hereditary material) is incorrect.

The "synthetic life" once praised as "the most important scientific research achievement in human history" was soon put aside. However, this occurred quietly, perhaps because the scientific community was afraid that people were paying too much attention or was afraid that people might ask why? The answer is that the academic community itself is in a state of confusion. No one directly stated that Dr. Venter's claim was ridiculous (In fact, it is absurd. If DNA could produce the cell, it should be a perpetual motion machine, and if DNA could produce the cell without consuming energy, then life on this planet would no longer need sunlight to reproduce). Additionally, no one has continued to espouse the claim of "synthetic life", and no one has questioned why this "highest achievement in molecular biology" has not won a Nobel Prize over the past 9 years. Neither Dr. Venter nor Dr. Joyce publicly continued to make their cases. Dr. Venter did not pose the following question to Dr. Joyce: If DNA is incapable of producing the cell, then is "modern genetics" incorrect? Nor did Dr. Joyce go further to claim that Dr. Venter's assertion was attributed to the basic, incorrect, idea behind "modern genetics".

This indicates that it may have been difficult for them to balance the beliefs of "modern genetics" with the facts of molecular biology. On the one hand, "modern genetics" has been a classical theory of great authority for 100 years; on the other hand, authoritative objective facts are important than any authority.

In theory, however, whether genes can produce cells (including traits) should depend on Mendel's assumptions regarding genes and not on what people can argue or discuss at will. Thus, we should go back to Mendel's original assumptions regarding genes to determine if genes, as defined by Mendel, are the producers of the individuals (including traits).

\section{Mendel's Assumptions regarding the Gene}

Mendel assumed: "if the tall variety contains in its germ cells something that makes the plants tall, and if the short variety carries something in its germ cells that makes the plants short". The "something" above is what was later called a "gene" [4]. 
From this assumption, Mendel did not think that the gene is the producer of tall (or short) or the producer of the plant. Instead, this assumption clearly tells us that the gene is the facilitator that makes the individual (plants) tall (or short). Remember that the gene is the facilitator rather than the producer. This is the basic idea of Mendel's assumption, and the key basis for judging which of the statements by Dr. Venter and Dr. Joyce is correct.

Apparently, Mendel considers that the gene does not produce tall (or short) or plant, but could frame plants to be tall (or short). Therefore, the gene is the element that frames and controls the specifications of the plant (individual).

Such facilitators that control product specifications are common in daily life. They often appear in the form of templates, drawings, molds and design schemes. For example, an aircraft factory contains drawings that can be used to make monoplanes and biplanes. One wing's drawing controls the specifications for one part (the wing) of the aircraft, and a set of drawings controls the specifications for the entire aircraft. In the same way, one gene (e.g., the tall-gene or short-gene) controls the specifications for one trait (tall or short, respectively), while an entire set of genes (genome) controls the specifications for an entire set of traits (e.g., a plant).

The facilitator is not the same as the producer, but it is a participant in the production of products having particular specifications. Being a facilitator logically implies the existence of its facilitating action's acceptor; without an acceptor, there would be no facilitator. In an aircraft factory, the acceptor is the aircraft production line. Thus, each aircraft is produced by the aircraft production line following the specifications defined in this aircraft's drawings. In Mendel's assumption, the acceptor can only exist in the gene-free part of the fertilized egg (today we know that this acceptor is the egg's transcriptase system [5]; however, this scientific discovery occurred in the second half of the 20th century. In Mendel's time there was no way to be sure), because the gene, as the facilitator, cannot also be the recipient of the facilitator. Each individual is produced by the gene-free part of the fertilized egg following the specifications defined in this individual's genes (genome). Therefore, just as an aircraft factory has two elements (the aircraft production line and aircraft design drawings), Mendel's assumption directly implies that the individual producer is made up of two elements. They are 1) the gene/genome (i.e., facilitator) and 2) the producing operator (i.e., recipient) located in gene-free part of the fertilized egg.

From the above analysis, we know that the original meaning of Mendel's assumptions regarding the gene was as follows: the gene is a hereditary element controlling product (individual, trait) specifications. It is able to make the gene-free part of the fertilized egg to produce products (individual, trait) in accordance with the specifications set by it. That is to say, the tall plants are produced by the gene-free part of the fertilized egg following the specifications defined in the genome containing the tall-gene, and the short plants are produced by the gene-free part of the fertilized egg following the specifications defined in the genome containing the short-gene. 
Thus, we can see that the original meaning of Mendel's assumption is surprisingly consistent with Dr. Joyce's aforementioned statement.

Please see: the DNA synthesized by Dr. Venter was the genome of Mycoplasma mycoides. According to Mendel's thought it should be the hereditary element controlling individual specifications. Namely, it is able to make the genefree part of the fertilized egg following the specifications it sets to produce a $M$. mycoides bacterium. This is exactly what Dr. Joyce states: "the second bacteria (an enucleated Mycoplasma capricolum, equivalent to the gene-free part of the fertilized egg) made all the proteins and organelles in the so-called 'synthetic cell' (belonging to $M$. mycoides) by following the specifications implicit in the structure of the inserted DNA".

This fully confirms that Mendel's assumptions regarding the gene were true, because Dr Joyce's words are supported by the scientific facts discovered over the past 76 years. Additionally, it also provides good circumstantial evidence that our interpretation (of Mendel's assumptions regarding the gene) is right.

\section{Objective Facts Prove That Real-World Genes (DNA) Are Truly as Defined by Mendel, and There Is No Evidence of the Existence of the So-Called Genes (DNA) of "Modern Genetics" That Act as the Hereditary Materials or the Producers of Individuals}

\subsection{The First Evidence Comes from Avery's Experiment}

In 1944, Avery et al. confirmed that genes are made of DNA and stated: "deoxyribonucleic acid (DNA) is capable of stimulating unencapsulated $R$ variants of Pneumococcus Type II to produce a capsular polysaccharide" [6]. This told us that DNA (gene) is not the producer of a capsular polysaccharide (trait); instead, the gene only is the facilitator (stimulator) that makes unencapsulated $\mathrm{R}$ variants of Pneumococcus Type II (as a producing operator) to produce a capsular polysaccharide. Namely, the unencapsulated R variants of Pneumococcus Type II (as a producing operator) produced a capsular polysaccharide by following the specifications implicit in the structure of the DNA (discovered by Avery et al). Avery's claim is entirely consistent with Mendel's assumptions regarding the gene (and Dr Joyce's previous statement).

This experimental evidence indicates that real-world genes (DNA) are truly as defined by Mendel, and there is no evidence of the existence of the so-called genes (DNA) of "modern genetics" as the hereditary materials or the producers of individuals.

\subsection{The Outline of Scientific (Molecular and Cellular Biology) Evidences}

Following the Avery experiment, there was considerable progress in biochemistry (including the later appearance of molecular biology) and cytology (including the later appearance of cellular biology), especially in areas involving DNA. 
The new findings included the transcription of DNA, the transcriptase and transcription factors, the base pairing principle, the genetic code, the discovery of RNAs and their respective functions, the confirmation of RNA's function producing protein, the confirmation of various proteins' (including various synthetic enzymes) functions, and the gradual and complete mastery of cell cycle knowledge. More than 100 Nobel Prize winners were among the scientists who made these contributions. These scientific achievements are now recorded in university textbooks and encyclopedias on the scientific fields (molecular biology, biochemistry, cytology, and cell biology).

In the vast scientific truth, it is enough to put forward the following four points: 1) All the cells (including cell products) on the earth are produced by the DNA-free part (the transcriptase system) of the cell following the specifications implicit in the structure of cell's DNA (genome). The production is accomplished using a natural, predetermined, automatic, cause-result continuous, procedural process (i.e., the cell cycle) initiated by genome transcription, but all the activities can be attributed to the genome being transcribed; 2) All the cells of a particular individual are products of their first cell (fertilized egg); therefore, each individual is produced by the DNA-free part of the fertilized egg (the transcriptase system) following the specifications implicit in the structure of the egg's DNA (genome). Thus, the genome's transcription (by the egg's transcriptase system) is the root cause of the individual being produced; 3) The genome controls the specifications of all the products of the individual. Because DNA is the template for producing RNA, it first controls the specifications of the RNA, then RNA controls the specifications of the protein, and finally the protein controls the specifications of other organic substances, such as lipids and carbohydrates; and 4) DNA has no producing capacity. In the process of an individual's formation, DNA does not consume energy, does not do work, and does not build 3', 5'-phosphodiester or peptide bonds.

The first two points show that the scientific truth is exactly the same as Mendel's assumptions. Genes (DNA) are not the producers of the individuals (cells) but the facilitators. All the individuals (cells) are produced by the DNA-free part of the egg (the transcriptase system) following the specifications implicit in the structure of the DNA (genome) of the egg (the cell). Additionally, the last two points confirm that genes (DNA) are pure elements that frame and control the specifications of the product (individual, cell) in the form of a template.

As with Avery's experiment, these objective facts also indicate that real-world genes (DNA) are truly as defined by Mendel, and there is no evidence of the existence of the so-called genes (DNA) of "modern genetics" as the hereditary materials or the producer of the individual.

\section{Conclusions}

Now we can be sure that the true idea of Mendel's assumption regarding the gene has been rediscovered. 
Rediscovering the original meaning of Mendel's assumption regarding the gene is the most significant discovery in genetics since Mendel's death because this meaning has never been recognized by the world. For about half a century before the birth of "modern genetics", few people knew of Mendel, and for the next 100 years, people were only exposed to the incorrect meaning provided by "Modern Genetics". This, of course, had consequences. The most serious consequence is that genes have become the basis on which "modern genetics" was established. A wrong theory would lead to absurdity. As a typical example, Dr. Venter believed he created "synthetic life" because he synthesized a genome.

Just as it was possible to research the sun, the earth, the moon, and the planets in the era of the Geocentric Theory, it was also possible to research genes, chromosomes, DNA, RNA, and transcriptase in the "Modern Genetics" era. However, the general direction of this science is wrong. If people insisted on following the Geocentric Theory, then because they think they have found the center of the solar system, they would never look for the center again, and they finally would never know where the center is. Similarly, if people insist on following "modern genetics", then because they think they have found the hereditary material (i.e. genes, while in reality the gene is only one element of the hereditary material), they would stop looking for the hereditary material, and they finally would never know what the hereditary material is. Consequently, people will never solve the mystery of life, and man-made life will never occur.

The correct theory of genetics is essential for, and a guarantee of, the normal development of genetics-based sciences.

Note: The author of this paper has published a paper on the same subject [7]. However, this paper focuses on "genes are templates rather than producers" and gives an in-depth analysis of the reasons why "modern genetics" treats genes as the hereditary material. Later, there were feedbacks that although they agreed with the conclusions of this article, their understanding of the consistency between Mendel's assumption and Dr Joyce's words was still vague. The author was prompted to write this article. When the basic framework of the paper is completed, the author found that the true idea of Mendel's assumption regarding the gene can be described in Dr. Joyce's language. With Dr. Joyce's reference, such a description is not only simple, but also particularly persuasive. It can be said that today, after the truth of the gene is revealed, the most appropriate expression language of the true idea of the Mendel's assumption regarding the gene could come on. Before, I understand the true idea of Mendel's assumption; however, how to persuade others always is very hard. Dr Joyce provided me with the most appropriate expression language. Only having been persuaded the world can realize that the true idea of Mendel's assumption regarding the gene has been rediscovered.

\section{Acknowledgements}

I thank Lesley Benyon, PhD, from Liwen Bianji, Edanz Group China 
(www.liwenbianji.cn/ac), for editing the English text of a draft of this manuscript.

\section{Conflicts of Interest}

The author declares no conflicts of interest regarding the publication of this paper.

\section{References}

[1] Gibson, D.G., Grass, J.I., Lartigue, C., Noskov, V.N., Chuang, R.Y., Algire, M.A., et al. (2010) Creation of a Bacterial Cell Controlled by a Chemically Synthesized Genome. Science, 329, 52-56. https://doi.org/10.1126/science.1190719

[2] Wade, N. (2010) Researchers Say They Created a "Synthetic Cell". New York Times.

[3] Germplasm (2019) Merriam-Webster Dictionary of Encyclopaedia Britannica. https://www.merriam-webster.com/dictionary/germplasm

[4] Morgan, T.H. (1928) The Theory of the Gene. Yale University Press, New Haven, 2.

[5] Zhou, M.Y. (2018) The Answer to the "First Question" in Genetics: The Hereditary Material. Open Access Library Journal, 5, e4645.

https://doi.org/10.4236/oalib.1104645

[6] Avery, O.T., MacLeod, C.M. and McCarty, M. (1944) Studies on the Chemical Nature of the Substance Inducing Transformation of Pneumococcal Types. Journal of Experiment Medicine, 79, 152. https://doi.org/10.1084/jem.79.2.137

[7] Zhou, M.Y. (2018) Mendel Actually Wants to Say: Genes Are Only One Element of the Hereditary Material. Open Access Library Journal, 5, e4941.

https://doi.org/10.4236/oalib.1104941 